La variabilidad como construcción de significado en el coro Indagando la experiencia interactiva de los coreutas Manuel Alejandro Ordás, Isabel Cecilia Martínez Epistemus - Revista de estudios en Música, Cognición y Cultura, 7(2), 27-56, e010, 2019 ISSN 1853-0494 | https://doi.org/10.24215/18530494e010 https://revistas.unlp.edu.ar/Epistemus Sociedad Argentina para las Ciencias Cognitivas de la Música (SACCoM)

\title{
La variabilidad como construcción de significado en el coro
}

Indagando la experiencia interactiva de los coreutas

\section{Manuel Alejandro Ordás e Isabel Cecilia Martínez ordasalejandro@fba.unlp.edu.ar}

Laboratorio para el Estudio de la Experiencia Musical (LEEM) - Facultad de Bellas Artes (FBA) Universidad Nacional de La Plata (UNLP), Argentina.

\section{Resumen}

En este estudio nos propusimos indagar acerca de las claves multimodales en las descripciones de primera persona de los coreutas -esto es, las percepciones e impresiones de los coreutas, sus actitudes, valores y concepciones acerca de su práctica en el coro- mediante la realización de un estudio cualitativo de entrevistas. Las respuestas mostraron que la idea de sistema de coro como una unidad predomina en las concepciones que tienen los coreutas cuando hablan acerca del logro de metas de uniformidad en la práctica del conjunto coral. También mostraron que los cantantes construyen su experiencia interactiva a partir de un cúmulo de claves multimodales de las que dan cuenta en sus relatos, cuando describen sus percepciones dentro de la propia cuerda, con otras cuerdas, con el director, y cuando expresan su sensibilidad con respecto a las claves sonoro-kinéticas vinculadas a los niveles de afinación y las percepciones temporales y espaciales.

\section{Palabras Clave}

coro, claves multimodales, interacción, variabilidad, análisis cualitativo. 


\title{
Variability as construction of meaning in chorus Inquiring the interactive experience of choristers
}

\begin{abstract}
In this study, we set out to investigate the multimodal keys provided in the choristers' descriptions (i.e., choristers' insights, impressions, attitudes, values and conceptions of their practice in the choir) through a qualitative study of interviews. Answers showed that the idea of chorus system as a unit prevails among choristers' conceptions when they refer to uniformity goal attainment in the practice of the choral ensemble. It has also been revealed that singers build their interactive experience from a cluster of multimodal keys that they account for in their narratives (when describing their insights within their own or other voice type, with the director, and when expressing their sensitivity regarding sonic-kinetic keys linked to tuning levels and temporal and spatial perceptions.
\end{abstract}

\section{Key Words}

choir, multimodal cues, interaction, variability, qualitative analysis. 


\section{Introducción}

Habitualmente, tanto el trabajo coral como algunos de los procedimientos para el logro de las metas interpretativas (por ejemplo, el trabajo de empaste vocal sonoro del conjunto) dan cuenta de una ontología de homogeneidad en el modelado de la práctica hacia el interior del coro. Una mirada diferente propondría una ontología alternativa. El conjunto coral podría asumirse como un enjambre dado que, tanto la percepción individual de los coreutas como la del director, en tanto ejecutantes, hacen referencia a una percatación consciente de la existencia de todo tipo de desajustes, variaciones de altura y temporales. Esta variabilidad ${ }^{1}$ percibida podría reflejar condiciones de adaptación y acoples internos dentro del grupo coral que son necesarios para controlar el equilibrio de su funcionamiento. La noción de enjambre se asocia al funcionamiento de un conjunto numeroso de individuos que registra en su interior una actividad variada, que se entiende como necesaria para mantener el equilibrio del todo. De acuerdo a esta noción, entendemos al coro como un conjunto de subjetividades que construyen el significado de su práctica en comunión, en base a claves multimodales cuyo rol consiste en brindar, tanto al director como a los coreutas, facilitadores para regular su desempeño durante la ejecución. Estas claves que facilitan la interpretación pertenecen a los dominios visual, auditivo, espacial y kinético, y permiten regular en la práctica de la ejecución coral aspectos característicos como la temporalidad, la afinación, y el timbre, entre otros. Participar en la práctica de un coro involucra que un conjunto múltiple de actores (cantantes y director, ambos intérpretes y ejecutantes) ponga en juego relaciones multimodales -donde hay claves visuales, auditivas y kinéticas-, relaciones afectivas y adecue su práctica a diferentes niveles de liderazgo que inciden en cómo se organiza la propia experiencia.

Existen antecedentes empíricos que abordan la intersubjetividad en la práctica del coro colocando el foco en el análisis de la incidencia de la disposición de las voces en la interpretación (Pele y Payri, 2013). Asimismo, se ha estudiado el efecto de aspectos acústicos de la ejecución instrumental en la coordinación temporal entre dúos (Palmer, Spidle, Koopmans y Schubert, 2013), el liderazgo en ensambles instrumentales (Timmers et al., 2014); la sincronía/empatía de los latidos del corazón mientras se canta en coro (Vickoff et al., 2013) o el impacto positivo del canto coral sobre la salud (Sanal y Gorsev, 2013). Si bien el coro generalmente funciona como una plataforma donde los participantes se sienten conectados entre ellos (Tonneijck, Kinebanian y Josephsson, 2008), implica una interacción entre la experiencia individual y la percepción de integridad, totalidad y plenitud que no debe perderse de vista. Los aspectos de la cooperación entre agentes no humanos también pueden brindar información útil para entender la cognición 
social en el coro. Específicamente en el campo de los estudios con insectos, también hay evidencias empíricas de comportamientos cooperativos, aunque solo aparentes; por ejemplo, en los estudios con cierta variedad de grillos y luciérnagas (Greenfield y Roizen, 1993; Backwell, Jennions, Passmore y Christy, 1998), dado que hacia el interior del grupo hay una competencia en la señal, múltiples señales compiten por la atención de una hembra, precediendo unas a otras por algunas decenas de milisegundos (competencia intra-grupo). En otros casos, la sincronía conjunta de los machos sirve para desviar su ubicación frente a depredadores (como medio de supervivencia grupo-individuo) y la sincronía perfecta de todos los miembros del grupo (por ejemplo, en las luciérnagas, que producen el denominado efecto faro) le permite a este grupo de machos competir por las hembras con otros grupos de machos (comportamiento social de competencia inter-grupo o grupo-grupo). No hay estudios que traten a la experiencia de relaciones de colaboración/competencia hacia el interior del coro; sin embargo, estos antecedentes constituyen el germen evolutivo sobre el cual se elabora y desarrolla el análisis posterior del entrainment entre músicos (Clayton, 2013). En dicho análisis se proponen tres niveles en los cuales es factible de ser estudiada la interacción entre los individuos, a saber: intra-individual, inter-individual (o intra-grupo) e inter-grupo. Podemos decir entonces que el concepto de entrainment es útil para describir con propiedad los tipos de interacciones que tienen lugar en la práctica coral. Cabe aclarar que, aunque Clayton (2013) se focaliza específicamente en la dimensión temporal de la interacción, sosteniendo que no habría investigaciones que sitúen al estudio del entrainment en una dimensión espacial, Leman (2008), en línea con nuestra concepción de la interacción en la práctica coral, define al entrainment como un fenómeno espacio-temporal y lo vincula con la teoría de la Cognición Musical Corporeizada (en adelante CMC). De esto se desprende que para el abordaje de un estudio acerca de la interacción dentro de los ensambles musicales (como es en nuestro caso el coro) se debe tener en cuenta que un ensamble es un sistema dinámico humano que se desenvuelve en el marco del complejo mentecuerpo-entorno multiindividual. Por ende, en la interacción intervienen factores cognitivo-corporales, sociales e intencionales que influyen en la performance.

Un abordaje de la actividad de los ensambles vocales desde la perspectiva del entrainment -como fenómeno espacio-temporal mediante el uso de técnicas de microanálisis apropiadas- permite comprender intenciones muy específicas por parte de los coreutas (como cantar adelantándose o retrasándose con respecto al beat, o enfatizar dinámicamente o realizar cambios en la articulación de determinados eventos rítmicos) y advertir los efectos potenciales que estos tipos de ajuste tienen en la dinámica de todo el grupo (para conocer los resultados alcanzados ver Ordás, 2018; Ordás y Martínez, 2017; 2018; 2019). 
Para indagar la experiencia de primera persona de los coreutas vinculada a su práctica hacia el interior del coro, se diseñó una entrevista semiestructurada que fue administrada a los miembros estables de un mismo grupo con el fin de obtener indicadores de su percepción desde su lugar como integrante individual en el coro, desde su lugar como integrante de la cuerda, y en cuanto a su percepción global del coro (Rubin y Rubin, 1995). Entendemos aquí la palabra percepción no únicamente en su acepción estricta en vinculación con la escucha, sino en un sentido más amplio de significaciones de la experiencia de primera persona; es decir, en vinculación al modo en que los integrantes del coro se perciben a ellos mismos dentro del coro, y cómo perciben a los otros en una variedad de aspectos.

Por todo ello, nos proponemos recoger la experiencia de primera persona hacia el interior del coro sobre la base de una serie de supuestos e interrogantes destinados a saber qué piensan unos coreutas de los otros y cómo se sienten frente al director. Se busca recolectar respuestas multimodales vinculadas a las actitudes, valores, la percepción de sí mismo y de los otros, vinculadas a la posición del sujeto en relación a la obra que está trabajando, al estado de la obra (inicial, durante, post) y a la diferencia del ensayo respecto del concierto, es decir, relativas a una cantidad múltiple de situaciones de participación del cantante en el coro.

\section{Método}

\section{Participantes}

Veintisiete coreutas participaron voluntariamente de las entrevistas semiestructuradas e individuales: 17 mujeres, 10 varones, edad promedio $=46,8, \mathrm{SD}=$ 15,5, y experiencia coral promedio de 8 años. La muestra estuvo conformada por las respuestas de 10 sopranos, 7 contraltos, 3 tenores y 7 bajos que forman parte del mismo coro.

\section{Caracterización Sociodemográfica del Coro Objeto de Estudio}

El coro participante del estudio fue creado por iniciativa del director fundador del mismo, en conjunto con la dirección ejecutiva del Hospital El Cruce-Alta Complejidad en Red Dr. Néstor Carlos Kirchner de Florencio Varela². El coro nace a partir de la voluntad institucional de conformar una actividad cultural que represente al mismo hospital, dado que una institución de salud de alta complejidad de estas características brinda un servicio de bienestar a la comunidad y, siendo la música pensada como un componente de práctica social enriquecedor, encuentra en la actividad de un coro su manifestación para toda la comunidad acorde a las 
necesidades institucionales de brindar los servicios de salud comunitarios que la misma provee. El coro nació en abril del año 2010, como un coro de nivel vocacional, con un repertorio en su mayoría compuesto por música popular urbana argentina y latinoamericana. Está conformado por 27 cantantes jóvenes y adultos en un rango desde 18 años hasta los 69 años (media $=46,8$ ), algunos incluso trabajadores de distintas áreas del mismo hospital. El resto de los integrantes, provienen de las comunidades de Florencio Varela, Quilmes, Berazategui, San Francisco Solano y zonas aledañas. Personas de ambientes muy diversos a las que las une sólo el gusto por cantar, donde ninguno es músico ni se dedica profesionalmente a la música, sino que desarrollan en su vida cotidiana diversas profesiones y ocupaciones. Tal es así que hay docentes, profesores, jubilados/as, empleados/as públicos, administrativos/as, profesionales de la salud y hasta jóvenes estudiantes universitarios de diversas carreras. Si bien no es excluyente el saber musical o la experiencia coral para integrar el grupo, las personas que ingresan realizan una audición previa a los efectos de evaluar la voz a modo de diagnóstico, principalmente enfocado en el aspecto registral y de salud vocal. Los registros vocales se dividen en las cuatro cuerdas típicas de la mayoría de los coros vocacionales mixtos y su distribución en cantidad de personas es la siguiente: 10 sopranos, 7 contraltos, 3 tenores y 7 bajos. El grupo ensaya dos horas, dos veces por semana en el mismo hospital. Si bien en su inicio los ensayos eran sólo una vez por semana, el carácter vocacional del grupo y las ganas de mejorar, sumados al interés y al compromiso de la institución con la actividad, hizo incrementar al doble la carga horaria. Esto impactó positivamente en el rendimiento musical del grupo, profundizando las relaciones interpersonales, y sumando momentos compartidos en el desarrollo de la actividad, como por ejemplo viajar a festivales corales. Los ensayos constan de un perfilamiento del trabajo vocal (respiración, autoconciencia corporal, posturas, emisión vocal, desarrollo auditivo-perceptivo) y la preparación del repertorio de obras para su interpretación. Desde la dirección del coro, estos aspectos implican además el desarrollo de la coordinación gestual y la construcción creciente de los criterios de conducción musical que la realización de cada obra demanda. Durante el desarrollo de la actividad, los participantes fueron adquiriendo las nociones técnicas del canto coral conjunto, y aunque todos los años hay un movimiento inevitable de gente que abandona y nueva gente que ingresa al grupo, se mantiene una base estable de cantantes que permite el crecimiento sostenido del coro.

El contexto de actuación del coro es variado y amplio con relación a su actividad artística. Participa en gran cantidad de conciertos, festivales y ciclos corales, tanto en su zona de influencia (zona sur del Gran Buenos Aires) como en la Ciudad Autónoma de Buenos, Aires y varias provincias argentinas. Su intensa actividad musical incluye además (i) la organización de un festival coral internacional, el Festival Coral Balcarce Canto y Raíces recibiendo en Balcarce (Provincia 
de Buenos Aires) a coros de todo el país y del extranjero; (ii) la realización de conciertos didácticos en escuelas, bibliotecas y en diversos eventos culturales; y (iii) la realización de producciones corales y/o sinfónico-corales independientes por encargo a su director. Además, se constituyó como una asociación civil sin fines de lucro para profundizar la difusión de la actividad coral en su medio, lo que llevó a recibir el reconocimiento como entidad de bien público por parte del Municipio de Florencio Varela.

La selección del repertorio que aborda el coro, en la mayoría de los casos queda a criterio del director, aunque siempre los cantantes sugieren la realización de distintas obras al momento de ir ampliando el repertorio, lo que muchas veces es aceptado y muy bien recibido por el director siempre y cuando esa obra se adapte a las características musicales del grupo. La conformación del repertorio tiene incumbencia con la programación anual y la inclusión de las obras propuestas por los coreutas configuran un incentivo para los cantantes al tratarse de obras cuya interpretación les resulta interesante, novedosa, desafiante. Por otro lado, para nuestra idea de comprender al coro como un organismo vivo e interactivo es importante saber escuchar (no en el sentido acústico de la palabra) sino atender a lo que el coro dice, reconociendo a su vez las individualidades, ya que muchas veces el coro no habla como un único organismo, como un todo uniforme, sino que hay muchas voluntades (a veces hasta enfrentadas) en un pedido, sugerencia, y el director debe poder saber leer esas individualidades también.

\section{Técnicas de Producción de la Información}

La elaboración de las preguntas de la entrevista estuvo guiada por las tesis emergentes de los marcos teóricos propuestos más arriba y por supuestos de corte etnográfico que emergen de nuestra propia práctica en el coro. La experiencia acumulada nos llevó a pensar que, si interrogamos a los coreutas acerca de su experiencia en el coro y favorecemos una comunicación amplia, emergerá de los relatos de experiencia un cúmulo de claves multimodales que dan cuenta de sus percepciones dentro de la propia cuerda, con las otras cuerdas, con el director, y de su sensibilidad con respecto a ciertas claves sonoro-kinéticas vinculadas con los niveles de afinación, las percepciones del tiempo y del espacio, y demás. En este sentido, se predijo que las respuestas de los coreutas permitirían agrupar el fenómeno de las claves multimodales resultantes en categorías que las ordenaran por tipo de interacción y por tipo de modalidad, a saber: claves multimodales en relación a sus compañeros de cuerda, claves multimodales en relación a su coro total, claves multimodales en relación a su director, claves multimodales con predominio visual, claves multimodales con predominio auditivo, claves multimodales de naturaleza temporal, claves multimodales de naturaleza espacial. 
Para el armado de las entrevistas semiestructuradas se confeccionó un guion que constó de cuatro ejes principales que sirvieron de guía para la confección de las preguntas: (i) lo referente a la experiencia del coreuta y su relación con el coro total, (ii) lo referente a la experiencia del coreuta en relación con su propia cuerda y con otras cuerdas, (iii) lo referente a aspectos intersubjetivos sentidos o percibidos durante la práctica entre coreutas y director, y (iv) lo referente al contexto de ejecución, sea en ensayos o conciertos. En cada uno de estos ejes, esperamos encontrar respuestas acerca del criterio de variabilidad y uniformidad. Estos ejes para conformar el guion de las entrevistas semiestructuradas se pensaron en base a las categorías de análisis que se utilizan en la literatura acerca de los estudios de ejecución, referidos a la práctica del coro (Louhivuori, Salminen y Lebaka, 2005; Tonneijck et al., 2008; Vickoff et al., 2013; Judd y Pooley, 2014; Sanal y Gorsev, 2014). Estos análisis incluyen la distinción entre la práctica en el ensayo y en el concierto, la noción y percepción de masa, como parte integrante de las cuerdas, y la experiencia individual del cantante, entre otras dimensiones. Cabe aclarar que excede a los propósitos de este estudio incluir la dimensión de las actividades sociales en el interior del coro (esto es, la participación en viajes, el bienestar social y para la salud que genera cantar en un coro, por mencionar solo algunas), y enfocar en la cuestión de ser cantante de coro, como es ese ser con otros, cuáles son las actitudes, los estereotipos, las concepciones de cantar en grupo.

Dentro de lo que se propone teóricamente para el estudio de la práctica en el coro, hay varios ejes factibles de analizar que conformarían las experiencias de estar en el coro, esto es, la experiencia dentro de la masa o sentirte integrante del coro, (que comunicaría uniformidad), la experiencia dentro de la cuerda o sentirte integrante de una cuerda (que comunicaría la diversidad o variabilidad), la experiencia individual o sentirte como individuo (que comunicaría también la diversidad o variabilidad), y la experiencia de ejecución durante el ensayo y el concierto o sentirte en el ensayo y el concierto.

De este modo, en las entrevistas se partió de los 4 ejes que guiaron las preguntas (basadas en la revisión de las categorías sobre las que se analiza la práctica en el coro, en el estado del arte), y en las respuestas fueron apareciendo distintos indicadores de uniformidad, diversidad, intersubjetividad y contexto. Una vez obtenidas todas las respuestas se realizó un análisis de contenido, y se identificaron 4 categorías principales de primer orden y a su vez se identificaron 13 categorías de segundo orden o dimensiones para cada una de ellas (ver Tabla 1).

\section{Procedimiento}

Se administraron veintisiete entrevistas semiestructuradas e individuales a los 
coreutas. Se sugirió a los participantes que al responder se explayaran tanto como desearan y que en cada pregunta vincularan su experiencia con todo aquello que consideraran necesario. Al inicio de la entrevista se indagó acerca de cómo y dónde entienden ellos el contexto de actuación social y cultural de la actividad de la que forman parte, además de completar datos personales acerca de su experiencia coral, registro vocal, y nivel musical. Los participantes respondieron a la entrevista luego de tener un cúmulo de experiencias en conciertos y en ensayos a los efectos de sustentar sus respuestas en su percepción de la práctica. Las entrevistas fueron administradas de manera escrita mediante una planilla confeccionada en el procesador de textos, de modo que el cantante dispusiera del tiempo necesario para pensar y reflexionar acerca de su experiencia de cantar en el coro, para luego ir escribiendo sus respuestas. Se utilizó el software QDA Miner 4 Lite v.1.4.6 (Provalis Research) para la categorización y codificación de las respuestas de los cantantes, empleando la técnica del análisis de contenido; y el software online Voyant-Tools (Sinclair y Rockwell, 2016) para el conteo de palabras. Luego de la categorización y codificación se utilizó la planilla de cálculo Microsoft Excel para organizar las categorías y dimensiones en un cuadro en relación a los reportes de los cantantes.

\section{Análisis de las Entrevistas}

La tarea de análisis constó de las siguientes etapas (Raimundi, Molina, Giménez y Minichiello, 2014):

1. A partir de la obtención de todas las respuestas, cuatro integrantes del equipo de investigación de pertenencia de los autores recibieron una copia de las transcripciones de las entrevistas. Se le pidió a cada uno que, de modo independiente, identifique las unidades de significado relevantes para el objetivo del estudio y se les asignó un código (codificación abierta). Seleccionamos otros fragmentos de acuerdo con aspectos conceptuales provenientes de las teorías adoptadas en esta investigación a los efectos de comprender nuestro objeto de estudio (categorización mixta).

2. Además, solicitamos desarrollar reglas explícitas para la lectura de las respuestas a partir del establecimiento de códigos (libro de códigos). De esta manera, quedó explicitado cómo segmentar el corpus y la manera en que se registraron los datos. Basándonos en las categorías propuestas confeccionamos fichas de análisis donde se consignó una palabra clave extraída del texto en su literalidad. Para el análisis de las respuestas se empleó una técnica de análisis cualitativo basada en el análisis de contenido y el conteo de palabras (Ryan y Bernard, 2003). Se procedió en primer lugar a agrupar las respuestas en términos de un número de categorías. Se 
utilizaron procedimientos de categorización y codificación (Hernández Sampieri, Baptista Lucio y Fernández-Collado, 2010). Las categorías clave se organizaron y formularon en un conjunto de dimensiones correspondientes.

3. Se realizó una comparación entre 1 y 2 , esto es, la selección de las unidades de significado y la descripción de categorías realizada por cada investigador. Se mantuvieron las categorías que resultaron más factibles de inferir y de emplear, con relevancia teórica, y resultantes del consenso entre los investigadores.

4. El trabajo de análisis requirió la participación de un segundo equipo de investigadores colaboradores, denominados procesadores de datos (Piñuel, 2002), a quienes se les brindaron las categorizaciones realizadas para la interpretación de los datos de segundo orden (dimensiones) que sirvieron para exponer y describir las conclusiones del estudio. Esta vez, tres investigadores realizaron de forma independiente una reelaboración de las categorías conceptuales, a partir de sucesivas tareas de definición de las categorías propuestas por separado y con relación a las restantes (codificación axial). Todo el procedimiento se orientó a establecer la credibilidad, dependencia y confirmabilidad de los datos (Hernández Sampieri et al., 2010), como criterios de rigor en la investigación cualitativa.

5. 5. El análisis cualitativo consistió en la obtención de respuestas que se sometieron a un análisis reiterado de contenido (Ryan y Bernard, 2003). Las respuestas se agruparon y categorizaron por similitudes. Se obtuvo a continuación el porcentaje de utilización de dichas categorías y la distribución de palabras clave, generándose nubes de palabras y analizándose mediante evidencia interpretativa los vínculos entre ellas. Por último, las categorías y dimensiones desprendidas del análisis determinaron finalmente el modo en el que los coreutas organizan sus percepciones cuando hablan acerca de su propia experiencia (ver Tabla 1).

\section{Resultados}

\section{Análisis de Contenido}

En la Tabla 1 se muestra la vinculación entre los supuestos de inicio y las categorías emergentes de los relatos a las que se arribó finalmente. Se presenta la manera de reducir la información recogida al transferir las respuestas. En las primeras dos columnas se observan las categorías y dimensiones obtenidas, y en 
la columna de la derecha se detallan los indicadores de sincronización multimodal que se utilizaron para analizar los reportes de los cantantes, diferenciándolos según se identifican descriptores de nivel intra-individual, inter-individual o intragrupo e inter-grupo (Clayton, 2013). Estas categorías nos sirven para explicar la experiencia en el coro en la dimensión individual (o intra-individual), intra-cuerda (o inter-individual/intra-grupo) e inter-cuerda/entre cuerdas (o inter-grupo).

\begin{tabular}{|c|c|c|}
\hline Categorías & Dimensiones & $\begin{array}{l}\text { Indicadores de sincroniza- } \\
\text { ción multimedial }\end{array}$ \\
\hline \multicolumn{3}{|l|}{ 1. Uniformidad de la masa } \\
\hline $\begin{array}{l}\text { Indicios del comportamiento de la } \\
\text { masa (el coro como grupo) y grupal } \\
\text { como un todo. }\end{array}$ & $\begin{array}{c}\text { Afinación (altura) } \\
\text { Timbre (color) } \\
\text { Dinámica (intensidad) } \\
\text { Temporalidad (timing) }\end{array}$ & $\begin{array}{c}\text { Desde una perspectiva interac- } \\
\text { tiva grupal. } \\
\text { Sesgo INTER-INDIVIDUAL } \\
\text { (INTRA-GRUPO) }\end{array}$ \\
\hline \multicolumn{3}{|l|}{ 2. Diversidad en la masa } \\
\hline $\begin{array}{l}\text { Indicadores de la variabilidad en la } \\
\text { experiencia sentida tanto a partir del } \\
\text { desempeño individual dentro de la } \\
\text { masa como parte integrante, como } \\
\text { de la percepción del resto de los } \\
\text { coreutas. }\end{array}$ & $\begin{array}{l}\text { Experiencia sentida de variabilidad } \\
\text { Experiencia percibida de variabilidad } \\
\text { Liderazgo (identificación) }\end{array}$ & $\begin{array}{c}\text { Desde la perspectiva individual. } \\
\text { Sesgo INTRA-INDIVIDUAL }\end{array}$ \\
\hline \multicolumn{3}{|l|}{ 3. Intersubjetividad } \\
\hline $\begin{array}{l}\text { Indicios del comportamiento interac- } \\
\text { tivo, ya sea en términos generales } \\
\text { o particulares a partir de cualquier } \\
\text { descriptor verbal que denote adap- } \\
\text { tación interactiva entre coreuta/s y/o } \\
\text { director. }\end{array}$ & $\begin{array}{c}\text { Claves temporales (percepción } \\
\text { temporal-sincronía interactiva-timing) } \\
\text { Claves auditivas (percepción auditiva- } \\
\text { acústica) } \\
\text { Claves espaciales (percepción } \\
\text { espacial-disposición) } \\
\text { Claves visuales (percepción visual) }\end{array}$ & $\begin{array}{l}\text { Desde una perspectiva en in- } \\
\text { teracción con la propia cuerda, } \\
\text { las otras cuerdas y el director. } \\
\text { Sesgo INTER-GRUPO }\end{array}$ \\
\hline 4. Contexto de acción & & \\
\hline $\begin{array}{l}\text { Percepción experiencial del } \\
\text { entorno físico de práctica según la } \\
\text { circunstancia en la que se produce la } \\
\text { interpretación. }\end{array}$ & $\begin{array}{l}\text { Situación de ensayo } \\
\text { Situación de concierto }\end{array}$ & \\
\hline
\end{tabular}

Tabla 1. Tabla de categorización y codificación en dimensiones emergentes de las respuestas comunes de los coreutas.

En línea con los supuestos acerca de la experiencia interactiva de los coreutas, de que dicha experiencia se construye en base a la identificación de claves multimodales, los cantantes efectivamente hablaron de sus impresiones, relativas a los aspectos individuales acerca de su participación dentro del grupo, acerca de su 
participación en la propia cuerda, acerca de sus percepciones acústicas, visuales, auditivas, espaciales y temporales, propias y de todo el coro, acerca de cómo se sienten en los ensayos a diferencia de los conciertos, y finalmente acerca de cómo interactúan con el director. Consignamos a continuación algunos ejemplos de las respuestas de los cantantes donde nos interesa destacar el modo en que describen su experiencia en términos de homogeneidad-heterogeneidad y uniformidaddiversidad, en cada una de las dimensiones analizadas, que configuran los modos de organizar su propia práctica a partir de claves multimodales:

\section{Categoría I: Uniformidad de masa}

Cuando hacen alusión al coro como una masa uniforme, los coreutas hablan utilizando términos que remiten a las categorías propias de la teoría de la ejecución musical, tales como la afinación, la dinámica, las articulaciones, el timbre, y los aspectos temporales principalmente basados en una idea de coro ideal, como si la meta que quisiera lograr el coreuta se basara únicamente en la búsqueda de la homogeneidad en base a la uniformidad de todos los aspectos de la ejecución a los que hace alusión:

“[...] En general percibo el sonido como muy armónico ya que considero que el cantar grupalmente hace que las voces se complementen con los otros registros y que dentro de una misma cuerda sus integrantes se ayudan mutuamente o se apoyan en alguno de los cantantes para seguir entonados. [...] Hay varios aspectos que considero. La entonación, es decir que todos estén cantando la misma nota, aunque a veces esto se confunde con el timbre de voz de cada cantante. Otro aspecto es el volumen, a veces hay voces más acaudaladas y otros que son más suaves o por falta de confianza o timidez cantan con menos volumen. Por último, puedo mencionar el tempo como otra característica. [...] Creo que ese sonido coral se logra con mucho ensayo, para mejorar los errores de entonación y volumen, como así también para conocer la voz de nuestros compañeros, tanto de nuestro registro como la de los demás registros, y también entender las indicaciones que da quien dirige el coro y lograr modificaciones que se indican. Creo hay que tener mucha seguridad de la parte que cantamos con nuestra cuerda para poder escuchar las otras y no confundirnos".

Sin embargo, en la mayoría de los relatos emerge igualmente el componente individual, cuando hablan de afinación:

“Considero que mi coro suena muy bien, siento una emoción muy grande al escu- 
charnos, y lo mejor es tener la certeza de que cada vez conseguimos más afinación, mejor calidad sonora".

En cuanto a los conceptos de sonoridad, color de las voces, y unificación del timbre, las respuestas emplean ideas tales como cuerda armoniosa, sonido armónico, y se refieren al sonido homogéneo como unión, armonía en el sentido de unión y en general vinculado a contenidos emocionales y afectivos:

"Mi percepción es que, cuando todos -sea por cuerda y todas las cuerdas juntasensayamos y actuamos con estudio y responsabilidad, el coro es un todo que suena bien y todos disfrutamos desde adentro y los espectadores que nos escuchan. También será importante el lugar de ensayo y presentación para un mejor sonido coral".

"Siento armonía, unión, me emociona escucharnos".

"Cuando estamos conectados entre nosotros, siento la vibración de las voces".

El componente dinámico lo vinculan mucho con el aspecto tímbrico, y al referirse a la intensidad, les resulta cómodo hablar del volumen de la ejecución identificando alguna voz en particular, una cuerda, o que la ejecución es el producto de una construcción global de la interpretación:

"Por momentos nos escuchamos como si hubiera más voces que las presentes y en otras oportunidades parece que somos menos que los que están”.

Respecto de la temporalidad se refieren a conceptos como sincronía y ensamble valorando la construcción conjunta y el concepto ajustado-desajustado cuando hablan de aspectos rítmicos de la performance:

"Escucho una sincronía constante entre mi voz y el resto del grupo coral".

Estos relatos pertenecientes a la categoría de uniformidad sugieren que, aunque el modelo de coro que tienen los cantantes se basa en la consolidación de la homogeneidad, buscando eliminar todo tipo de variabilidad, la mayor parte del tiempo describen su experiencia reconociendo múltiples variabilidades al hablar acerca de su práctica. El gráfico de la distribución de categorías (Figura 1) per- 
mite observar con qué frecuencia apareció cada dimensión según el número de respuestas.

\section{Uniformidad de la masa}

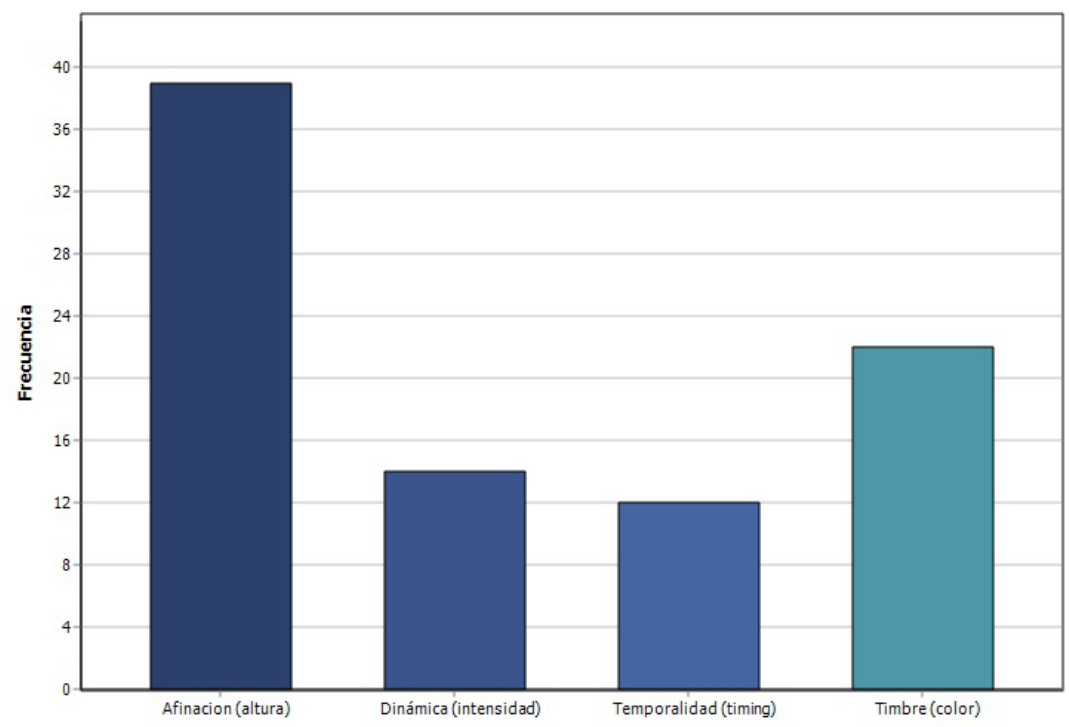

Figura 1. Cantidad de respuestas para cada una de las dimensiones de la categoría (1) Uniformidad de la masa. Sobre un total de 87 respuestas, el 44,8\% se refiere a la afinación, el 25,3\% al timbre, el $16,1 \%$ a la dinámica, y el $13,8 \%$ a la temporalidad. Los números en el eje y corresponden a la cantidad de veces que aparece cada una de las dimensiones indicadas en el eje x.

En la Figura 1 observamos que la mayor cantidad de respuestas corresponde a los relatos acerca de la afinación (44,8\%), y en menor medida al timbre $(25,3 \%)$, la dinámica $(16,1 \%)$ y la temporalidad $(13,8 \%)$. Esto nos invita a pensar en la idea de que, para la uniformidad de la masa, la experiencia de la afinación es uno de los aspectos más importantes a tener en cuenta en la búsqueda de homogeneizar el sonido. La afinación también podría representar la información más confiable o la señal honesta acerca de la calidad del grupo. Una interpretación posible de estos resultados puede vincularse al hecho de que los participantes integran un coro vocacional, y por ende el logro de la afinación constituye una preocupación que persiguen con mucha más asiduidad que en otras agrupaciones vocales. 


\section{Categoría 2: Diversidad en la masa}

Esta categoría agrupa los indicadores de la variabilidad en la percepción, tanto a partir del desempeño individual dentro del coro como parte integrante, como de la percepción del resto de los coreutas. Se destacan sobre todo sus percepciones acerca de la pertenencia a la propia cuerda, pero advirtiendo el movimiento interno. Por ejemplo, cuando hablan de su experiencia de la variabilidad, hacen alusión a la resonancia con la música, con los otros, rescatando lo individual en lo grupal:

"Cuando las escuchaba a las sopranos antes de entrar al coro me sonaban ángeles todas y una me encantaba, pero ahora también me gusta porque somos más, pero me gustaría trabajar más la homogeneidad de todas, por eso mi interés de bajar mi tono".

En este caso, la participante reconoce la diversidad y realiza modificaciones en su performance para lograr la homogeneidad. La experiencia percibida de la variabilidad se vincula al sentimiento propio ya que el coro está en permanente interacción de acuerdo al modelo comunicativo multidireccional de claves multimodales:

"En mi caso particular percibo que la nota solicitada suena en mi cabeza correctamente, pero a la hora de emitirla vocalmente temo al error, por lo que el grupo ayuda a desinhibirme en ese aspecto".

"Sí, estuve como público y sólo escuchaba una melodía con acompañamiento, o la cuerda que se destacaba más en cada obra que presentaron. Dentro de él pude percibir que cada cuerda tiene cosas mucho más ricas y pensadas para que se vayan complementando entre sî".

La identificación de los distintos aspectos de liderazgo dentro de las cuerdas y entre cuerdas es otra de las formas en las que encontramos la percepción de la variabilidad interna:

"Me considero una guía para la cuerda, no siempre funciona como una única entidad".

"Mi cuerda cuando está completa y las coreutas no compiten entre ellas suena muy bien porque hay voces fuertes, algunas más agudas, y otras más dulces, pero cuesta un poco aún armonizar, y a nivel grupal nos falta poder llegar a escuchar a las otras 
cuerdas sintiendo cómo cada una encaja haciendo la perfección del sonido porque por separados somos solo ruido, y juntos somos canción”.

El análisis de la distribución de las dimensiones pertenecientes a la categoría experiencia de variabilidad (Figura 2) arroja como resultado que la mayor parte de los relatos remiten a reconocer la diversidad hacia el interior del coro en términos de liderazgos internos (42\%) que se dan cuando los participantes hablan de voces que guían la cuerda, tal como se consigna en el testimonio precedente; las voces líderes son las más afinadas dentro de la cuerda o que tienen más años de experiencia en el canto coral: "[...] los que agarran la parte rápidamente [...] siempre hay un referente que lleva la cuerda adelante" o que se destacan acústicamente en términos de dinámica y articulación: "Una de las voces que más escuché [...] tiene una voz que se destaca siempre por su claridad y por lo fuerte que canta”.

2. Diversidad en la masa

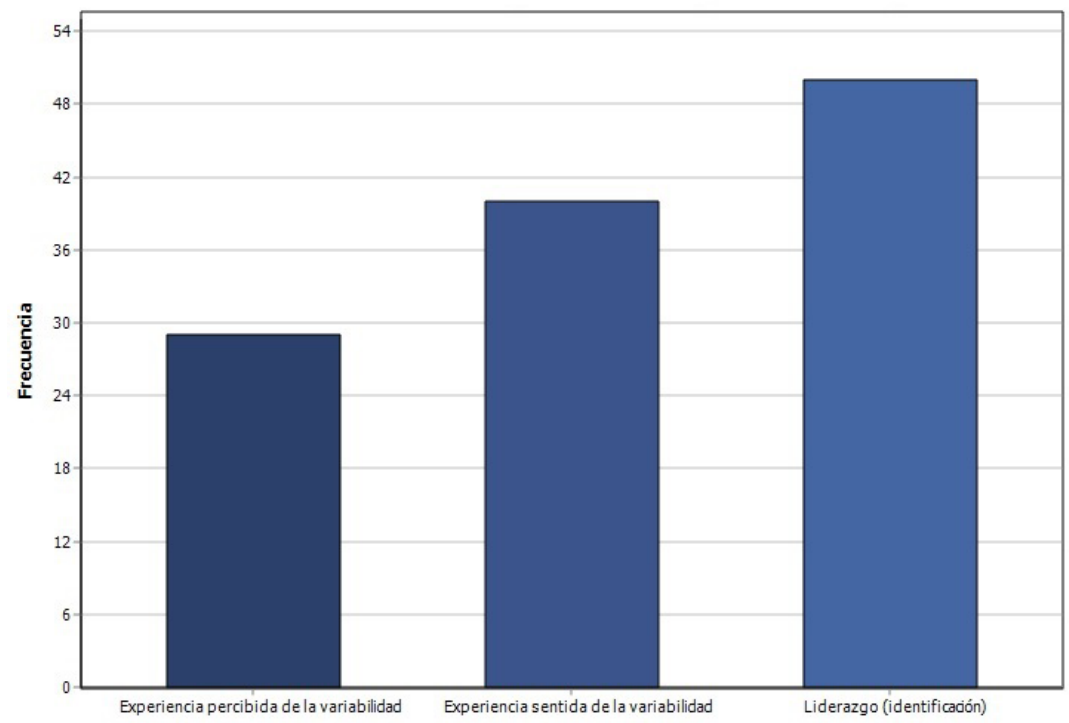

Figura 2. Cantidad de respuestas para cada una de las dimensiones de la categoría (2) Diversidad en la masa. Sobre un total de 119 respuestas, el 42\% se refiere al liderazgo, el 33,6\% a la experiencia sentida de la variabilidad, y el 24,4\% a la experiencia percibida de la misma. Los números en el eje y corresponden a la cantidad de veces que aparece cada una de las dimensiones indicadas en el eje x.

La emergencia de estos descriptores corrobora nuestros supuestos respecto de que la voz coral no es unívoca ni es una sola, el empaste no es uno solo, la cuerda 
no es una sola y el coro no es una única entidad desde la propia experiencia, sino que observamos que hay una nutrida descripción de diversidad y variabilidad desde la perspectiva de primera persona en el coro.

\section{Categoría 3: Intersubjetividad}

Rescatamos el aspecto intersubjetivo de la práctica en el coro dado que los cantantes comparten los significados de manera multimodal y brindan indicios del comportamiento interactivo para regular su desempeño, ya sea en términos generales o particulares a partir de las claves temporales, auditivas, espaciales y visuales que dan cuenta de tal adaptación cooperativa. Desde el aspecto intersubjetivo temporal, dijeron cosas como:

"Este es un punto en el cual, desde mi forma de escuchar, todas las cuerdas tenemos que sincronizar y escucharnos más todos".

En torno a las claves auditivas y espaciales se advierte en los relatos la percatación de la influencia que tiene en lo personal el estar con el otro haciendo algo en conjunto y cómo lo que el otro hace mejora la propia acción:

"Estoy dentro de ese sonido, ya no como espectador. Pertenezco a ese sonido".

"El hecho de cantar juntos, cerca y escuchándonos mejora mi sonido vocal y me da confianza, seguridad y tranquilidad".

"Agrupados por cuerda uno se siente más relajado con el apoyo del compañero".

Relacionado a las claves visuales, aunque desde una perspectiva tradicional las ubicaríamos principalmente en todas aquellas pistas que obtienen los coreutas del director para regular su desempeño, en muchos casos observamos que la importancia de las claves visuales para construir la práctica también depende de la interacción con otros miembros del coro, además del director:

"Este ejercicio de complementarse obviamente no es individual, muchas veces nos miramos o simplemente nos quedamos en silencio hasta tener mayor seguridad".

Los resultados sugieren que los cantantes conciben la práctica coral desde 
una perspectiva intersubjetiva al contarnos su experiencia como parte del grupo, aunque persigan como meta la uniformidad de la masa (Figura 3).

\section{Intersubjetividad}

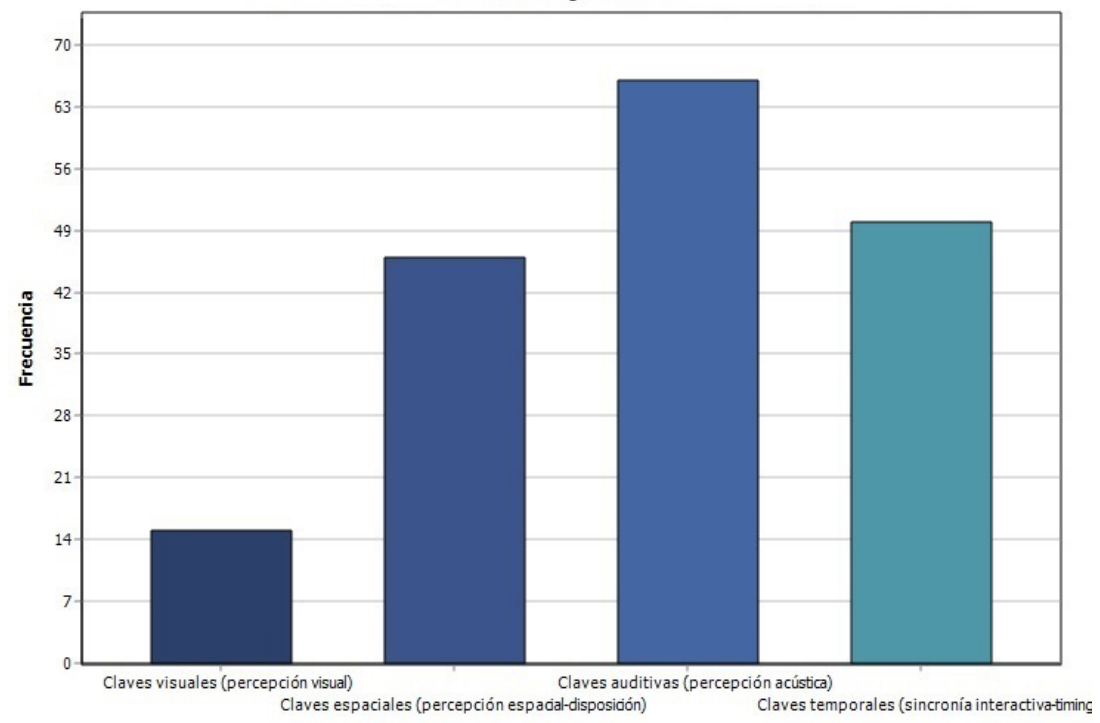

Figura 3: Cantidad de respuestas para cada una de las dimensiones de la categoría (3) Intersubjetividad. Sobre un total de 177 respuestas, el $37,3 \%$ se refiere a las claves auditivas, el $28,2 \%$ a las claves temporales, el $26 \%$ a las claves espaciales, y el $8,5 \%$ a las claves visuales. Los números en el eje y corresponden a la cantidad de veces que aparece cada una de las dimensiones indicadas en el eje $\mathrm{x}$.

Los reportes indican que por más que se reconozca el modelo de unidad para la definición de coro (el coro ideal, cómo debería sonar), cada coreuta construye su significado a partir de claves o pistas que obtiene de sus pares de manera intersubjetiva: ve los movimientos del director y de sus pares, escucha durante toda la ejecución, interactúa rítmica, sonora y kinéticamente en una espacialidad compartida en el tiempo. Los resultados interpelan, por un lado, a aquellos supuestos tradicionales que conciben a la práctica coral desde una perspectiva asimétrica y subordinada (director-dirigidos) de una sola vía; muestran por un lado que la comunicación de significados se comparte de manera multidireccional; y por otro enfatizan la pregnancia de las claves auditivas a la hora de regular el desempeño coral. 


\section{Categoría 4: Contexto de acción}

Con relación al contexto donde se desarrolla la práctica del coro, vimos que es muy importante para los cantantes hablar acerca del entorno físico de práctica y que según las circunstancias en las que se produce la interpretación, la experiencia se modifica. Estas descripciones las observamos cuando en las respuestas aparecen comentarios que separan las situaciones de ensayo de las de concierto:

"En todas las ocasiones hay que destacar la importancia del director del coro, cómo nos trasmite el sentir de la música, de cómo se debe ejecutar, de cómo nos marca los tiempos en los ensayos".

"En una situación de ensayo siempre estamos más distendidos, es un momento de aprendizaje: podemos equivocarnos y volver a repasar nuestras partes hasta que salga bien".

Aunque algunos relatos como estos sugieren que el componente de aprendizaje es fundamental a la hora del ensayo, lo cual denota la construcción de la interpretación, hay algunos coreutas, sin embargo, que piensan en términos de ensayos para la corrección de errores y en el concierto para finalmente expresarse, lo que abona los viejos debates acerca de la separación entre la técnica y la expresión:

"Sí, cambia bastante, el ensayo está para corregir los errores y modificar aquellas partes que son necesarias para expresar lo mejor de uno en un concierto".

Sin embargo, desde la práctica profesional de la dirección del coro intentamos profundizar en los aspectos intersubjetivos que promueven la experiencia de cantar en coro, de compartir el tiempo juntos, de construir esa realidad subjetiva de manera interactiva y disfrutarla haciendo música:

"Eso hace que cuando cantamos en un concierto sea importante demostrar todo eso, que amamos lo que hacemos, director y coreutas más allá de la nota y más allá de todo".

Resulta muy interesante, además, observar cómo varios de los coreutas destacan el rol del director desde un lugar de construcción social, como si estuvieran pidiendo de alguna manera que se contemple el papel emocional de la práctica, que se compartan significados, que se transmita algo más que indicaciones propias de la ejecución concertada: 
"El director creo que juega un papel importante, porque él es el que da seguridad al grupo, confianza, estímulo antes de salir a cantar, por supuesto un director totalmente diferente en el ensayo".

En referencia a la categoría contextual, no observamos mayores diferencias en la cantidad de respuestas respecto de las dimensiones referidas a situaciones de ensayo $(47,4 \%)$ y de concierto $(52,6 \%)$ (Figura 4$)$.

\section{Contexto de acción}

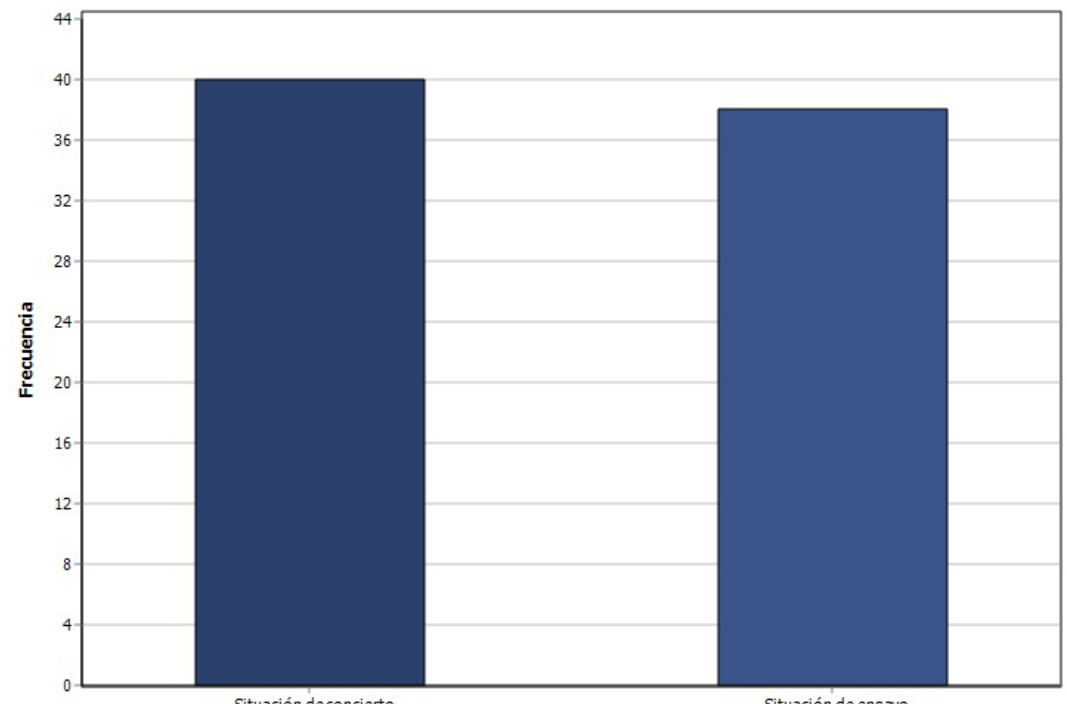

Figura 4. Cantidad de respuestas para cada una de las dimensiones de la categoría (4) Contexto. Sobre un total de 78 respuestas, el $52,6 \%$ se refiere a la situación de concierto, y el 47,4\% a la situación de ensayo. Los números en el eje y corresponden a la cantidad de veces que aparece cada una de las dimensiones indicadas en el eje $\mathrm{x}$.

Esto nos dice que, al hablar de la experiencia de cantar en coro, los relatos describieron las situaciones de ensayo y concierto como instancias necesarias y complementarias, aunque en sus respuestas encontramos un cierto sesgo de separación entre el desarrollo de la técnica (vocal, y en términos de correcciones de errores) reservado para los ensayos y la interpretación-expresión (y transmisión del contenido emocional) más dirigido a los conciertos.

Esto podría resultar útil para interpelar nuestra propia práctica como direc- 
tores. Entendemos que deberíamos propender al desarrollo de una concepción integral de construcción de significados que andamien la interpretación, y que esa construcción promueva retroalimentación a manera de espiral entre los ensayos y los conciertos. De este modo generaríamos que el modelo de comunicación intersubjetivo dialogue también entre los contextos de actuación (las impresiones y percepciones del ensayo se alimentan de las impresiones y percepciones del concierto y viceversa). Abandonando la idea de ensayo-concierto como instancias de desarrollo de la técnica y comunicación de la expresión respectivamente, entendemos que el reconocimiento de una interacción satisfactoria entre estos contextos genera niveles crecientes de mutualidad (Malloch y Trevarthen, 2008) y viabiliza una mejor interpretación. Rescatamos un comentario de uno de nuestros bajos que, en referencia a esto, nos dijo que:

"Hacer música es comunicar algo, sean palabras, notas, sonidos... y si uno tiene en claro eso que comunicará, aunque no salga lo más correcto posible, se entenderá, y ahí está el germen que luego generará la música".

Por último, presentamos una visualización gráfica de las dimensiones que, basadas en el análisis de contenido completo, muestran la mayor utilización de los descriptores en vinculación con las categorías 1, 2, 3 y 4 de uniformidad y diversidad de masa, intersubjetividad y contexto de acción, respectivamente (figura 5).

Luego de analizar las cuatro categorías por separado, resulta interesante observar cómo es la relación entre éstas con respecto al porcentaje de su utilización al describir la experiencia. Observamos que hay una predominancia de descripciones en relación a las dimensiones de la categoría 3 (intersubjetividad), por lo que la mayor parte de las respuestas rescatan el comportamiento interactivo en términos de las claves multimodales (38,4\%). Esto nos indica que la experiencia se construye desde una perspectiva de interacción en la propia cuerda, con las otras cuerdas y con el director. En particular, las claves auditivas, temporales y espaciales son las que están más presentes en las respuestas. Podemos decir que las fuentes sonoras de patrones temporales influyen en la interacción o coordinación temporal entre coreutas y director.

En segundo lugar, se ubica la categoría 2 (que también da cuenta de la variabilidad) principalmente con respecto a la identificación de liderazgos hacia el interior del coro $(25,8 \%)$. Las categorías restantes 1 y 4 (correspondientes a descriptores de uniformidad y contexto) tienen una distribución similar en los relatos (18,9\% y 16,9\% respectivamente). Lo que resulta interesante notar es que, reduciendo y vinculando todas las respuestas a cada categoría, la idea de variabilidad (categorías 2 y 3 ) sigue permaneciendo con fuerza al describir la experiencia 
(64,2\%), aun cuando el coro -desde una perspectiva tradicional- busque eliminar esa variabilidad en pos de la uniformidad. Uniformidad perseguida en torno a las mismas claves multimodales que se analizaron -homogeneidad respecto al ritmo y sincronización o timing (claves temporales), a la afinación, articulación, timbre o color vocal (claves sonoro-kinéticas); a la distribución espacial o formación coral (claves viso-espaciales); a los movimientos de los cantantes con restricciones culturales propias de la práctica (claves visuales).

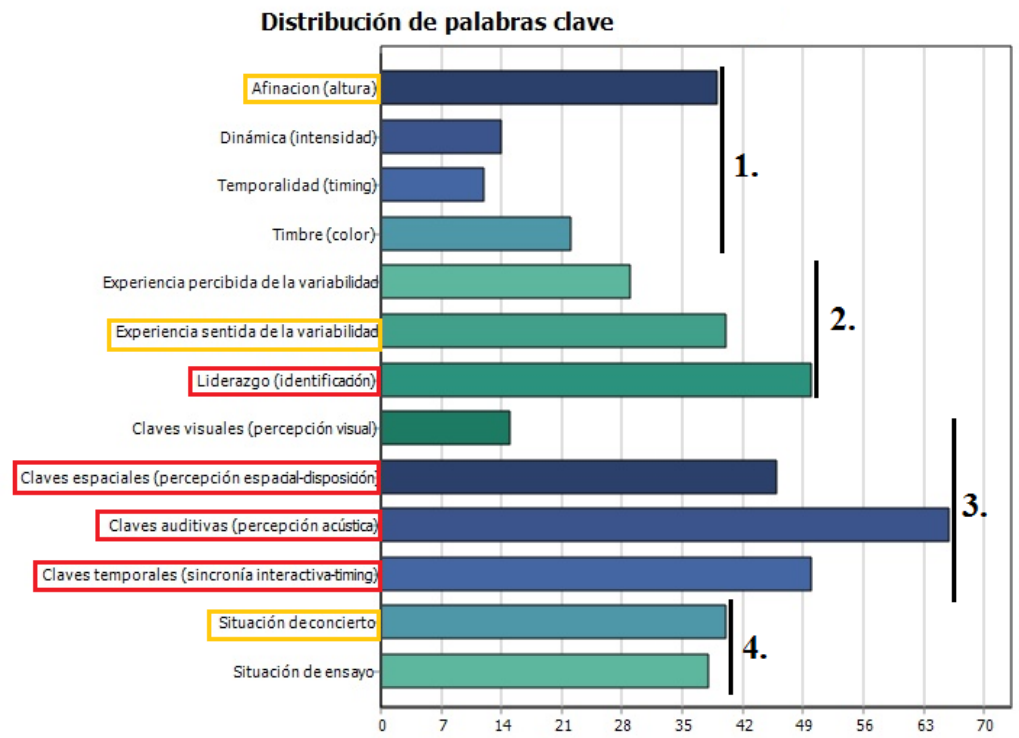

Figura 5: Cantidad de respuestas para cada una de las dimensiones de las categorías 1, 2, 3, y 4. Sobre un total de 461 respuestas, el 38,4\% se refiere a 3-Intersubjetividad, el 25,8\% a 2-Diversidad en la masa, el 18,9\% a 1-Uniformidad en la masa, y el 16,9\% a 4-Contexto de acción. Los números en el eje x corresponden a la cantidad de veces que aparece cada una de las dimensiones indicadas en el eje y señaladas las de mayor porcentaje en los relatos.

Las distintas situaciones de participación que se describieron y agruparon en las categorías resultantes permitieron aproximarnos a comprender cómo intervienen las claves multimodales que integran la práctica en el coro. 


\section{Conteo de Palabras}

Mediante esta técnica cualitativa dividimos los análisis de las entrevistas para obtener resultados en torno a (i) la frecuencia de utilización de palabras en todas las respuestas; y (ii) la frecuencia de utilización de palabras clave para describir la experiencia como integrante del coro.

\section{Frecuencia de palabras de todas las respuestas}

De todas las respuestas al amplio cuestionario administrado, se encontraron similitudes en la utilización de palabras para describir la experiencia, lo que se presenta como resultado en la Figura 6.

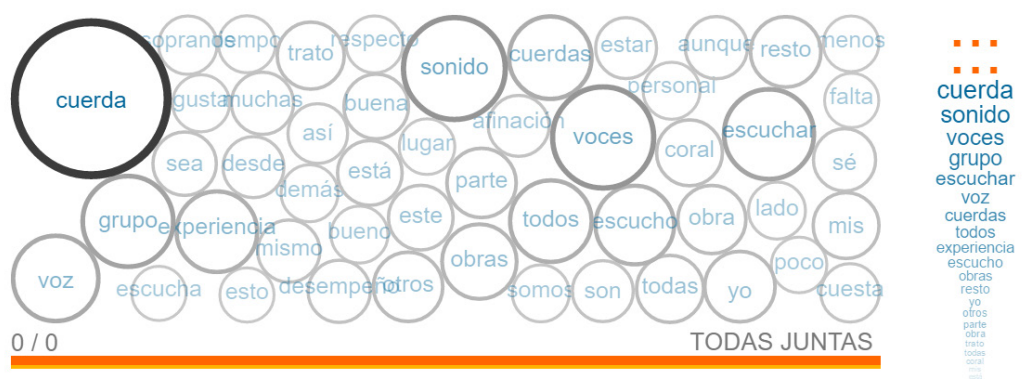

Figura 6. Visualización del conteo de palabras frecuentes. La columna de la derecha muestra una lista con las palabras de más alta frecuencia. El tamaño relativo de las burbujas indica la frecuencia comparada con otras palabras.

Estos resultados en vinculación con el análisis de contenido sugieren que, entre todo el repertorio de palabras de las que dispone el coreuta para hablar acerca de su experiencia, cuando se le pide que se explaye, la mayor parte del discurso se basa en la utilización de términos que aluden a la concepción del coro como una unidad, esto es, se tiende a pensar en términos de uniformidad. Sin embargo, las palabras más utilizadas, cuerda, sonido, voces, grupo denotan un cierto componente de pertenencia a subgrupos dentro de la unidad. Esto quizás se deba al factor social inherente que posee la práctica en el coro poniendo el foco en el aspecto intersubjetivo. La frecuencia de utilización de estas palabras como manera de fundamentar la experiencia habla de un modo de concebir el canto coral. El concepto de cuerda hace referencia al grupo, ambos términos hablan de la pertenencia. Las voces siguen aludiendo al conjunto (no emerge la palabra voz, sino voces) y el sonido vocal es el que se erige como medio de producción principal. Resulta interesante notar que 
si bien los coreutas hablan de las cuerdas aludiendo a la masa uniforme, también hablan del movimiento interno dentro de la cuerda, y reconocen liderazgos dentro del grupo con respecto a la intensidad, a la afinación, y a todos los aspectos descriptos en el análisis de contenido; es decir que, si bien desde el discurso el modelo de unidad en el coro se comunica con claridad (la mayoría de los cantantes dice o reconoce que lo que debe sonar es la masa, o la uniformidad) hay un gran reconocimiento de la variabilidad interna, vinculado a las claves multimodales, principalmente en relación con las claves sonoro-kinéticas (ver figura 5).

A partir de la obtención de la nube de palabras (figura 6), ubicamos aquellas palabras de más alta frecuencia (o palabras clave) dentro de los relatos, y éstas fueron vinculadas a otras palabras contenidas en las mismas respuestas. Esta interpretación constructiva, tiene el objeto de conocer y reflexionar acerca de algunos de los términos a los que los cantantes hicieron referencia dentro del mismo contexto, y que a su vez podrían constituir nuevos significados que aporten un mayor interés en las descripciones de la experiencia emergente en las respuestas.

Con base en evidencia eminentemente interpretativa, y producto de la lectura reiterada de los reportes, observamos que los cantantes establecen diversas y llamativas relaciones con otros términos al hablar acerca de la cuerda (de la propia y las demás), el sonido del coro, y al referirse a las voces en los intentos por describir su experiencia en el coro. En sus relatos, los coreutas utilizan una gran cantidad de palabras que tienen que ver con la idea de totalidad o unidad, con el empleo de términos y frases tales como: grupo, todos en la cuerda, todas las voces, sonido armónico, sonido coral, el sonido coral se logra, que ubicamos en la línea de las ideas de coro ideal que persigue esa meta. También aparecen otras palabras que ponen de manifiesto la idea de individualidad desde la perspectiva de primera persona: percibo el sonido armónico, escuchar las voces, voces femeninas, escuchar el sonido coral, el sonido que logra la cuerda, el resto de la cuerda/voces (que denota individualidad en el conjunto). Así, vemos que la dualidad uniformidad-diversidad está permanentemente presente en los cantantes en términos de metas de la ejecución y el auto-monitoreo o control momentáneo de la ejecución.

\section{Frecuencia de palabras clave}

Para realizar este análisis se seleccionaron las respuestas a una sola de las preguntas de la entrevista que invitaba al participante a resumir en pocas palabras su experiencia como integrante del coro (ver 1.3 en Información ampliatoria). De todas las respuestas a esta pregunta específica emergieron 4 palabras clave por recurrencia de utilización (figura 7) 


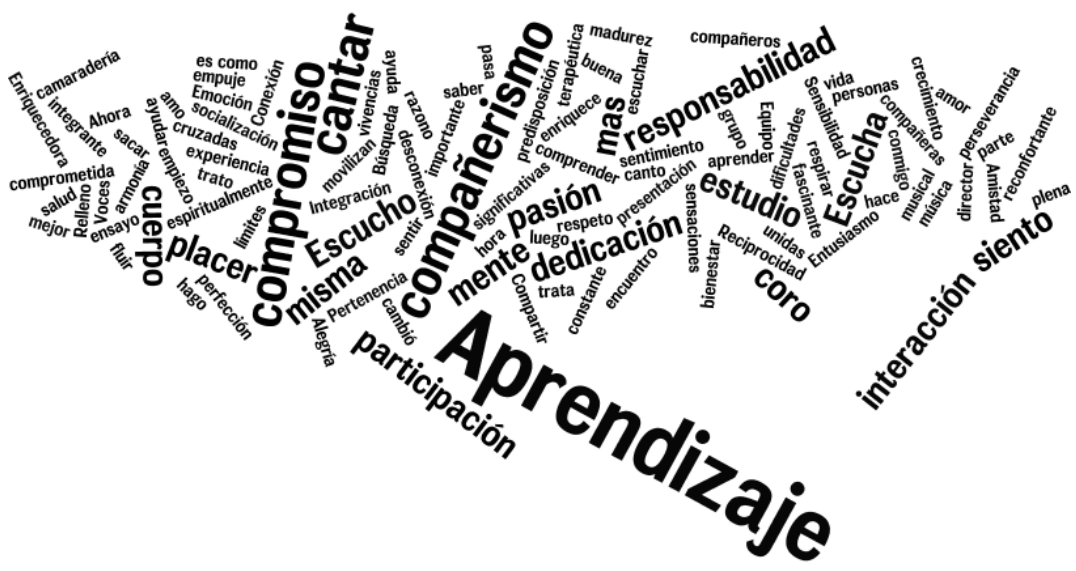

Figura 7. Nube de palabras donde se visualizan los términos de mayor frecuencia en las respuestas.

En la nube de palabras de la Figura 7, observamos que los términos más frecuentemente utilizados para definir su experiencia como integrantes del coro fueron aprendizaje, compañerismo, compromiso y por supuesto la palabra cantar, en referencia a la cual había una alta probabilidad de que surgiera debido a que cantar es justamente el principal modo de producción de esta práctica con lo cual no la tomaremos en cuenta para este análisis, pero sí más abajo en relación a los términos más próximos. Realizamos esta pregunta porque estimamos encontrar una suerte de síntesis de los participantes de lo que significaba su experiencia en el coro, apelando a que, al hacerlo en pocas palabras, pudiéramos inferir de todas las respuestas que surgieron, las concepciones de coro que poseen estos participantes. Y no de cualquier coro, sino del cual están hablando, esto es, de su coro, en el que participan como integrantes, el coro del cual forman parte, que hacen juntos, y del que, por lo tanto, son el coro. Resulta muy interesante ver que mayoritariamente se ve al coro como un espacio de aprendizaje, esto podría deberse a que es un coro vocacional, por lo tanto, la gente que va a cantar, viene de distintos ámbitos y en ese espacio común que comparten hay una vinculación entre el director como maestro y los coreutas como alumnos. En el coro se aprenden las obras, se aprende a cantar en muchos casos (a afinar, a respirar), se aprende y se conoce música nueva, se aprende algo que luego se comunica, se aprende a compartir una meta común. No podemos afirmarlo empíricamente mediante el análisis de estas entrevistas, pero sí nos atreveríamos a decir que habría una tendencia a considerar 
al coro como un entorno de aprendizaje para gran parte de los coros vocacionales. Las otras dos palabras relevantes, compromiso y compañerismo, también vislumbran lo que se fue viendo en el análisis de toda la entrevista, que es la incidencia del aporte individual frente al grupal, el compromiso es personal, de cada uno para con el grupo, mientras que el compañerismo está dando cuenta de una cualidad que, si bien se logra con el aporte de cada uno, es grupal, se necesita otro u otros para acompañarlo o ser compañero. A su vez, son cosas que el mismo coro fomenta y desarrolla desde adentro desde su formación, especialmente este coro objeto de estudio.

Continuando con la relectura interpretativa de los relatos en busca de intentar trazar vínculos con términos que aparecen en las frases o descripciones donde se ubican las palabras clave emergentes, observamos que los coreutas utilizan palabras tales como interacción, significativas, escucha, amistad, bienestar, dedicación, mente, movilizan, amor, y estudio. Notamos, por ejemplo, que cuando aparece la palabra amistad en los relatos de los coreutas, es frecuente encontrarla vinculada a compañerismo y compromiso en la misma frase o idea. Aquí entendemos que habría una predominancia a describir un contexto de construcción conjunta, el compromiso individual por el grupo y el estudio favorece a incrementar el compañerismo por medio de la amistad y el amor (a lo que uno hace y también al otro). Ambas cosas generan bienestar. El aprendizaje resulta significativo, con dedicación se aprende a escuchar, por ejemplo. La interacción también aparece repetidamente en los relatos como un descriptor muy fuerte de la experiencia en el coro. Todas estas palabras que encontramos en las descripciones vislumbran en su mayoría aspectos intersubjetivos, es decir que una palabra que eventualmente indicaría un aporte individual, aparece ligada inmediatamente a otra que indica unidad, construcción, colaboración. La idea de construcción conjunta de significados se identifica muy claramente. Ligada a cantar aparece frecuentemente la figura del director, pero también la de los compañeros, y la de la mente: "Cantar en armonía" como dicen algunos relatos, también está relacionado a los compañeros y al director, es decir, "estamos todos conectados para generarlo". Para finalizar, destacamos un relato clave que claramente está posicionado desde una perspectiva corporeizada de la experiencia rescatando el aporte de la CMC como una manera de comprender la práctica en el coro:

"Como integrante del coro, es reconfortante, me encuentro conmigo misma empiezo a comprender lo que le pasa a mi cuerpo y mente con la música, esas sensaciones que siento en mi cuerpo y mente que me movilizan y cantar con mis compañeros me hace sentir parte de un todo". 


\section{Discusión}

En este trabajo indagamos cómo piensan los coreutas acerca de su relación con sus compañeros y con su director en términos de las claves multimodales de las que disponen para coordinar y regular su desempeño. La información relevante que recolectamos de la actividad del coreuta dio cuenta de las percepciones individuales, hacia adentro de la cuerda y en relación al coro total. Entendiendo como percepciones al conjunto de claves multimodales que regulan el entonamiento corporeizado del coreuta (Leman, 2008), es decir, la experiencia de estar con el otro, de percibir el movimiento del otro, la afinación global y local de la cuerda, el modo en que se percibe al director, sus movimientos y sus señas. Vimos también que, aunque los cantantes reconocen el modelo de uniformidad para definir la práctica, cuando tienen que hablar de su propia experiencia, este modelo no resulta suficiente. Los participantes del coro hablaron de la propia cuerda y de las otras cuerdas haciendo referencia en su relato al concepto de masa uniforme; sin embargo, también hablaron de la variabilidad interna y del movimiento interno de la cuerda, reconociendo liderazgos dentro de la totalidad que no provienen únicamente del director, sino también que emergen de sus descripciones respecto del volumen y la afinación. Encontramos que, aunque los coreutas manifiestan que deben sonar como una única entidad, uniforme, y donde no se perciban desajustes de ningún tipo, en el análisis hacia el interior del coro, las respuestas reflejan que hay un reconocimiento de la variabilidad en términos de heterogeneidades de todo tipo, vinculada a las claves multimodales, en particular a las claves sonorokinéticas.

En base a estos resultados, entendemos que la búsqueda de la homogeneidad se construye en base a la diversidad; es decir que se vincula al modo de construir una sonoridad, una señal honesta (Van Noorden, 2010) a partir de la diversidad. En esta línea de pensamiento, la diversidad ya no debería ser vista como algo negativo, sino como parte de la construcción del significado. Desde la perspectiva tradicional de la práctica coral, en pos de la búsqueda de la homogeneidad se intenta anular la variabilidad en múltiples sentidos: restringir el movimiento corporal, restringir la disposición espacial de las cuerdas, homogeneizar la vestimenta y, sobre todo, controlar la variabilidad en los aspectos sonoros (timbre, afinación, articulación, etc.). De acuerdo a los resultados del estudio, postulamos que la variabilidad también es dependiente de la experiencia construida y percibida del rol concertante.

Los cantantes describieron su experiencia percibida y organizaron su relato respecto a (i) claves auditivas cuando hablan de las voces que se escuchan más para ser guiados por ellas musicalmente, cuando identifican la saliencia de deter- 
minadas voces por cuestiones relacionadas al timbre, o por cuestiones relacionadas a la percepción de las jerarquías dentro de la textura (como distinguir a aquel que canta la melodía) pero sobre todo cuando incluyen un sentido de pertenencia al sonido logrado, (ii) claves espaciales cuando hablan de su disposición dentro de la cuerda, las ventajas y desventajas de tener cerca a determinadas cuerdas para mejorar el empaste, o al director, (iii) claves visuales, cuando hablan de ver al director pero también cuando manifiestan complementarse mirándose con el resto de los compañeros, (iv) claves temporales cuando hablan en términos de sincronía interactiva multidireccional; lo que confirma que la comunicación entre los participantes del coro es multidireccional e intersubjetiva y la meta de homogeneidad intra e inter-cuerdas en la obra coral se logra mediante un proceso interno de heterogeneidad manifiesto en la variabilidad sonoro-kinética. El análisis de las respuestas de los reportes confirma nuestro supuesto de que la experiencia del coreuta es, en este caso, multimodal, y de que, en la relación con el coro, las claves sobre las que se construye el significado son inherentemente multimodales. Podemos afirmar también que la ejecución en el coro se construye mediante un proceso comunicativo multidireccional y dinámico producto de las relaciones intersubjetivas entre los distintos actores intervinientes.

Con respecto a la intersubjetividad y a los indicadores de sincronización multimodal los resultados informan acerca de la emergencia de una idea de vaivén dinámico hacia el interior de las cuerdas, y de los individuos con el director y viceversa. El coro expresivo interactúa con fuerzas dinámicas que generan tensiones y equilibrios producto del interjuego del componente expresivo, y no producto de la mera sujeción a una dominación.

Indagar acerca de la experiencia individual de los cantantes en el coro permite percibir hacia el interior del mismo lo que se concibe como una masa uniforme y homogénea en el resultado artístico final. Caracterizar la variabilidad de la experiencia interna implica describir un aspecto que aparenta no ser francamente variable, o al menos no tan variable internamente -como muestra el presente caso- en el escenario interactivo de las variaciones intra-grupo.

\section{Agradecimientos}

Esta investigación fue posible gracias al soporte de la Secretaría de Ciencia y Técnica de la Universidad Nacional de La Plata (Proyecto B349 y PRD Res.929/19). Se agradece especialmente a la Lic. Mariel Giménez (UBA-CONICET) por sus aportes y comentarios para la revisión del presente trabajo. Asimismo, el primer autor también agradece la contribución del traductor público Jonatan Codesido. 


\title{
Notas
}

\begin{abstract}
${ }^{1}$ Los términos variabilidad y diversidad se usan indistintamente a lo largo del escrito sin pretender establecer una diferencia entre ellos, y de acuerdo al sentido que tiene dentro de la oración en la que aparezcan.
\end{abstract}

${ }^{2}$ Para más información, ver el sitio web del Hospital El Cruce: http://www.hospitalelcruce.org/.

\section{Referencias}

Backwell, P., Jennions, M., Passmore, N., y Christy, J. (1998). Synchronized courtship in fiddler crabs. Nature, 391(6662), 31-32. doi:10.1038/34076

Clayton, M. (2013). Entrainment, Ethnography and Musical Interaction. En M. Clayton, B. Dueck, y L. Leante (Eds.), Experience and Meaning in Music Performance (pp. 188-207). New York: Oxford University Press. doi:10.1093/acprof:o so/9780199811328.003.0002

Greenfield, M. y Roizen, I. (1993). Karydid synchronous chorusing is an evolutionarily stable outcome of female choice. Nature, 364, 618-20. doi:10.1038/364618a0

Hernández Sampieri, R., Baptista Lucio, P., y Fernández-Collado, C. (2010). Metodología de la investigación, 5ta ed. México, D. F.: McGraw-Hill.

Judd, M., y Pooley, J. A. (2014). The psychological benefits of participating in group singing for members of the general public. Psychology of Music, 42(2), 269-283. doi:10.1177/0305735612471237

Leman, M. (2008). Embodied Music Cognition and Mediation Technology. Cambridge, MA y Londres: The MIT Press. doi:10.7551/mitpress/7476.001.0001

Louhivuori, J., Salminen, V-M., y Lebaka, E. (2005). Singing togther: A cross-cultural approach to the meaning of choirs as a community. En P. S. Campbell, J. Drummond, P. Dunbar-Hall, K. Howard, H. Schippers, y T. Wiggins (Eds), Cultural Diversity in Music Education: Directions and Challenges for the 21st Century K, (pp. 81-94). Bowen Hills, Queensland: Australian Academic Press.

Malloch, S. y Trevarthen, C. (2008). Communicative Musicality. Oxford: University Press.

Ordás, M. A. (2018). Variabilidad temporal hacia el interior del coro: Un estudio de claves multimodales y timing expresivo en la práctica coral. En M. A. Ordás, M. Tanco e I. C. Martínez (Eds.), Experiencia, producción y pensamiento. Libro de resúmenes de las Jornadas de Investigación en Música, (pp. 87-89). La Plata: Laboratorio para el Estudio de la Experiencia Musical (LEEM), Facultad de Bellas Artes, Universidad Nacional de La Plata. 
Ordás, M. A. y Martínez, I. C. (2017). La actividad temporal en la cuerda del coro. Un estudio de timing expresivo. En N. Alessandroni y M.I. Burcet (Eds.), La experiencia musical: abordajes desde la investigación, la interpretación y las prácticas educativas. Libro de resúmenes del $13^{\circ}$ Encuentro de Ciencias Cognitivas de la Música (pp. 65-66). Buenos Aires: SACCoM.

Ordás, M. A. y Martínez, I. C. (2018). Expressive timing in choir: An interactive study between choristers and conductor. En R. Parncutt y S. Sattmann (Eds.), ICMPC15/ ESCOM10: Abstract book (electronic) (p. 291). Graz, Austria: Centre for Systematic Musicology, University of Graz.

Ordás, M. A. y Martínez, I. C. (2019). Claves multimodales en la comunicación intersubjetiva del Coro. En Alessandroni, N., Torres Gallardo, B., y Beltramone, C. (Eds.). Vocalidades: la voz humana desde la interdisciplina (pp. 367-417). La Plata: GITeV.

Palmer, C., Spidle, F., Koopmans, E., y Schubert, P. (2013). Temporal coordination in vocal duet performances of musical rounds. En R. Bresin y A. Askenfelt (Eds.), Proceedings of the Stockholm Music Acoustics Conference (pp. 678-682). Stockholm: KTH Royal Institute of Technology.

Pelé, A., y Payri, B. (2013). Percepción interna y externa de la distribución de las voces en un coro gospel. Epistemus. Revista De Estudios En Música, Cognición Y Cultura, 2(1), 179206. doi:10.21932/epistemus.2.2716.0

Piñuel, J. (2002). Epistemología, metodología y técnicas del análisis de contenido. Estudios en Sociolinguística, 3(1), 1-42.

Raimundi, M. J., Molina, M. F., Giménez, M., y Minichiello, C. (2014). ¿Qué es un desafío? Estudio cualitativo de su significado subjetivo en adolescentes de Buenos Aires. Revista Latinoamericana de Ciencias Sociales, Niñezy Juventud, 12(2), 521-534. doi:10.11600 /1692715x.1221110414

Rubin, H. J. y Rubin, I. S. (1995). Qualitative interviewing. The art of hearing data. Thousand Oaks, CA: Sage.

Ryan, G. W. y Bernard, H. R. (2003). Data management and analysis methods. En N.K. Denzin, N.K. y Lincoln, Y.S. (Eds.) Collecting and interpreting qualitative materials. $2 a$ ed. (pp. 259-309). Thousand Oaks, CA: Sage.

Sanal, A. M., y Gorsev, S. (2014). Psychological and physiological effects of singing in a choir. Psychology of Music, 42(3), 420-429. doi:10.1177/0305735613477181

Sinclair, S. y Rockwell, G. (2016). Voyant Tools. Sitio web: http://voyant-tools.org/.

Timmers, R., Endo, S., Bradbury, A., y Wing, A. M. (2014). Synchronization and leadership in string quartet performance: a case study of auditory and visual cues. Front. Psychol., 5, 645. doi:10.3389/fpsyg.2014.00645 
Tonneijck, H. I. M., Kinebanian, A., y Josephsson, S. (2008). An exploration of choir singing: Achieving wholeness through challenge, Journal of Occupational Science, 15(3), 173-180. doi:10.1080/14427591.2008.9686627

Van Noorden, L. (2010). The functional role and bio-kinetics of basic and expressive gestures in activation and sonification. En Godøy, R. I. y Leman, M. (Eds.), Musical Gestures: Sound, Movement, and Meaning, (pp. 154-179). New York: Routledge.

Vickhoff, B., Malmgren, H., Åström, R., Nyberg, G., Ekström, S.-R., Engwall, M., y Jörnsten, R. (2013). Music structure determines heart rate variability of singers. Frontiers in Psychology, 4, 334. doi:10.3389/fpsyg.2013.00334

\section{Acerca de los autores}

\section{Manuel Alejandro Ordás}

ordasalejandro@fba.unlp.edu.ar

Músico, docente e investigador. Doctor en Artes, Licenciado en Dirección Coral y Profesor Superior de Música egresado de la Facultad de Bellas Artes, Universidad Nacional de La Plata. Se formo en la especialidad con los maestros Sergio Siminovich, Pablo Cánaves, Mariano Moruja, Santiago Santero, Antonio Russo, Ariel Alonso, Néstor Andrenacci, Gottfried Hoffman, Marco Berrini, entre otros. Creo y dirigió diversos grupos corales interpretando todo tipo de repertorio e Integró el coro de Cámara de la UNLP y el GCC-Grupo de Canto Coral. Es profesor adjunto de las cátedras de Dirección Coral I- II-III y Metodología de las Asignaturas Profesionales de la FBA-UNLP y dicta cursos de Práctica Coral y Cuidados de la voz en la EMBA Carlos Morel de Quilmes. Es docente investigador categorizado de la UNLP donde obtuvo becas doctorales y posdoctorales por concurso. Integra el Laboratorio para el Estudio de la Experiencia Musical (LEEM-FBA-UNLP) y el proyecto de investigación B349-Música, cognición y experiencia: modos de elaboración del sentido en contextos sociales de práctica música. Actualmente se desempeña como director coral, profesor en el nivel universitario y terciario superior, es becario posdoctoral de la UNLP e investiga los aspectos de la experiencia musical que intervienen en la performance coral.

\section{Isabel Cecilia Martínez}

isabelmartinez@fba.unlp.edu.ar

Isabel Cecilia Martínez es Dra. en Psicología de la Música por la Universidad de Roehampton Surrey, Reino Unido, Licenciada y Profesora en Educación musical (Fba-UNLP) y pianista. Es Profesora Titular de Metodología de las Asignaturas Profesionales y Audioperceptiva 1 y 2 en la Facultad de Bellas Artes de la UNLP. Es Directora del LEEM (Laboratorio para el Estu- 
dio de la Experiencia Musical-FBA-UNLP). Dirige investigadores, becarios y tesistas en cognición musical corporeizada en el marco de los proyectos Música, Cognición y Experiencia: Modos de Elaboración del Sentido en Contextos Sociales de Práctica Musical (2018-2021) de la Universidad Nacional de La Plata y PICT 2013-0368 (ANPyCT). Ex Presidente de SACCoM. Investiga aspectos de la cognición musical corporeizada y el pensamiento imaginativo en música, la recepción y la ejecución musical. Ha publicado y difundido su investigación en el ámbito nacional e internacional. 